\title{
Effect of Annealing on Crystal Orientation and Electrochemical Performance of Nanocrystalline $\mathrm{LiFePO}_{4}$
}

\author{
Wen-Li Kong ${ }^{1}$, Yi-Jie Gu ${ }^{1, *}$, Hong-Quan Liu ${ }^{1}$, Yun-Bo Chen ${ }^{2}$, Jie Yang ${ }^{1}$, Cheng-Quan Liu ${ }^{3}$ \\ ${ }^{1}$ College of Materials Science and Engineering, Shandong University of Science and Technology, \\ Qingdao 266510, China \\ ${ }^{2}$ Advanced Manufacture Technology Center, China Academy of Machinery Science and Technology, \\ Beijing 100044, China \\ ${ }^{3}$ Henan ZhongPingHanBo New Energy Co., Ltd., Pingdingshan 467000, China \\ *E-mail: 13792900643@163.com
}

doi: $10.20964 / 2018.03 .44$

Received: 14 November 2017 / Accepted: 2 January 2018 / Published: 5 February 2018

\begin{abstract}
Nano single-crystalline $\mathrm{LiFePO}_{4}$ (LFP) with large (010) plane exposure was synthesized by the hydrothermal method, followed by annealing to alleviate the main limitations of $\mathrm{LiFePO}_{4}$ cathode material. The XRD results indicated that after annealing, the sample gained the preferred crystal orientation with a (020) crystallographic direction. Annealed $\mathrm{LiFePO}_{4}$ showed a significantly improved capacity and excellent cycling and rate stability. Further electrochemical impedance analysis indicated that annealed $\mathrm{LiFePO}_{4}$ has smaller film resistance $\mathrm{R}_{\mathrm{sf}}$, smaller charge-transfer resistance $\mathrm{R}_{\mathrm{ct}}$, and a larger diffusion coefficient of lithium ion $\left(\mathrm{D}_{\mathrm{Li}}\right)$.
\end{abstract}

Keywords: $\mathrm{LiFePO}_{4}$; annealing; crystal orientation; electrochemical impedance

\section{$\underline{\text { FULL TEXT }}$}

(C) 2018 The Authors. Published by ESG (www.electrochemsci.org). This article is an open access article distributed under the terms and conditions of the Creative Commons Attribution license (http://creativecommons.org/licenses/by/4.0/). 